\title{
O PROCESSO DE DESERTIFICAÇÃO NO MUNICÍPIO DE ACARI/RN E AS ALTERNATIVAS DE PERMANÊNCIA PARA SEUS MUNÍCIPES
}

The process of desertification in the country of Acari/RN and the alternatives to stays for the dwellers

El proceso de desertificación en el municipio de Acari / RN y las alternativas restantes para sus residentes

GIRLENE EDSON DE OLIVEIRA AMARO

Especialista em Educação Ambiental Geografia Semiárido

MARIA LUIZA DE MEDEIROS GALVÃO

Doutoranda no

Programa de

Planejamento

Energético

Ambiental

UFRJ/IFRN

KETTRIN FARIAS BEM MARACAJÁ Universidade Federal de Campina Grande, Unidade Acadêmica de Administração e Contabilidade Centro de Humanidades.

Submetido em 01.12.2015. Aprovado em 10.05.2016 Avaliado pelo processo de double blind review.

\section{RESUMO}

O presente trabalho analisa o meio ambiente no município de Acari/RN, com foco na desertificação. Aborda o conceito de desertificação na visão de ACCIOLY (2011), ROSA (1974) e GALVÃO (2012) que identificam suas possíveis causas. Ainda, elenca as possíveis alternativas para permanência dos habitantes no município. Apresenta aspectos ambientais inerentes ao processo de desertificação do município de Acari, identificando algumas de suas potencialidades e fragilidades. A discussão teórica reflete sobre os núcleos de desertificação no Semiárido brasileiro que é formado pelo Polígono das Secas. Também, permite pensar no núcleo de desertificação Seridó e em sua vegetação caatinga. Proporciona uma visão do município de Acari, sua localização, povoamento e atividades econômicas. Por fim, apresenta os resultados da pesquisa de campo realizada com pessoas que trabalham em olarias, cerâmicas e faç̧ões.

Palavras-chave: Região do Seridó, Acari/RN, desertificação, caatinga.

\section{ABSTRACT}

This paper analyzes the environmental in the municipality of Acari/RN, focusing on desertification. It discusses the concept of desertification from the point of view of ACCIOLY (2011), ROSA (1974) and GALVÃO (2012) that identify its possible causes. It also lists the possible alternatives for the maintenance of the inhabitants of Acari in their municipality. It presents environmental aspects inherent to the process of desertification in the municipality of Acari, identifying some of its strengths and weaknesses. The theoretical discussion reflects on the nuclei of desertification in the Brazilian semiarid region that is formed by the Drought Polygon. It also permits to think about the Seridó's desertification core and its caatinga vegetation. It provides an overview of the municipality of Acari, its location, population and economic activities. Finally, it presents the results of a field research conducted with people working in brick kilns, ceramics and facções (small clothing factories).

Keywords: Seridó Region, Acari/RN, desertification, caatinga vegetation.

\section{RESUMEN}

Este trabajo analiza el entorno ambiental en el municipio de Acari / RN, centrándose en la desertificación. Se discute el concepto de desertificación en vista ACCIOLY (2011), Rose (1974) y Galvão (2012) que identifican posibles causas. También enumera las posibles alternativas para el mantenimiento de los habitantes del municipio. Presenta aspectos ambientales inherentes al municipio de proceso de desertificación Acari e identificar algunos de sus fortalezas y debilidades. La discusión teórica refleja en los centros de la desertificación en la región semiárida de Brasil que se forman por la Sequía Polígono. Además, vamos a pensar en la desertificación Seridó núcleo y su vegetación de sabana. Proporciona una visión del municipio de Acari, su ubicación, la población y las actividades económicas. Finalmente, presenta los resultados de la investigación de campo llevados a cabo con personas que trabajan en alfarería, cerámica y facciones.

Palabras clave: Estado Seridó, Acari / RN, la desertificación, la sabana. 


\section{INTRODUÇÃO}

Desde os primórdios da humanidade, o homem procura se fixar em um local que possa satisfazer suas necessidades e assim tornar esse espaço fixo para sua morada. Objetivando sua sobrevivência, o homem vivência um processo de deslocamento buscando constantemente por água e alimentos tendo que sair do seu habitat natural e descobrir novos territórios. Na contemporaneidade, muitos seres humanos sofrem com questões semelhantes às do passado, tendo de lutar por sua sobrevivência em áreas que não favorecem o seu desenvolvimento e nem suas necessidades de água e alimentos.

Da mesma forma que os nossos antepassados se fixavam em localidades onde existiam mananciais de água, muitas pessoas atualmente procuram por local semelhante. No Brasil, uma grande parte da região Nordeste sofre com a estiagem, ou seja, com a escassez de chuva, o que agrava o quadro de: sede, fome, pobreza, doenças e desigualdades sociais. Com essa problemática da insuficiência de chuvas na região, outras dificuldades vão aparecendo, e a mais agravante é a desertificação, objeto do nosso estudo.

No Nordeste, o Rio Grande do Norte está entre os mais susceptíveis à desertificação, sendo a região do Seridó, a que apresenta área de maior abrangência do fenômeno. Nela, tomamos como objeto de estudo o município de Acari, situado na porção oriental. A figura abaixo, mostra no mapa do Brasil, as áreas atingidas pela desertificação no Nordeste com as ocorrências de maior impacto e as áreas mais atingidas.

Figura 1: Áreas atingidas no Brasil pela desertificação

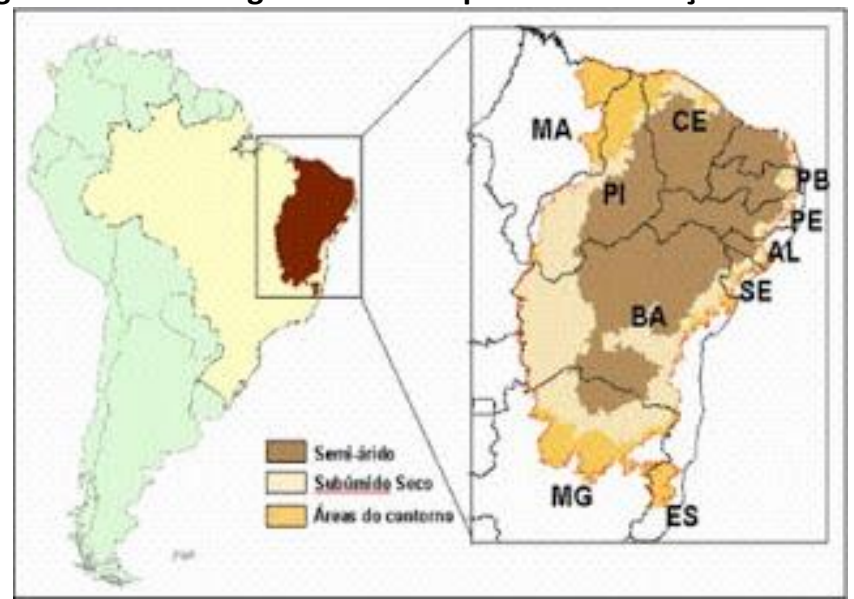

Fonte: http://www.tvebrasil.com.br/salto/boletins2005/dsa/meio.htm.Acesso em: 20 mai/2014.

Pode-se perceber os núcleos de desertificação no Nordeste e as áreas que necessitam de uma atenção especial por parte dos governantes e de toda sociedade. Assim, esse trabalho tem como objetivo geral analisar o quadro ambiental atual no município de Acari, tendo como problema a questão da desertificação. Como objetivos específicos: apontar os desafios encontrados para permanência dos habitantes no município; identificar as consequências da desertificação e propor uma atividade pedagógica para melhorar a educação ambiental no município de Acari.

A escolha desse tema decorreu da nossa preocupação com a saída permanente de moradores, principalmente jovens que não encontram oportunidade de trabalho no município, após terminarem seus estudos e se profissionalizarem, e assim, se deslocam para outras regiões do país em busca de trabalho e melhores condições de vida. Ainda muitos 
pais de família que saem da zona rural e passam a morar na zona urbana por causa da seca, deixam a cidade também e procuram emprego em outras localidades.

Segundo dados do Instituto Brasileiro de Geografia e Estatística (IBGE, 2010), o município de Acari tem 11.035 habitantes, sendo 8.902 na zona urbana, e 2.133 na zona rural. Tal resultado demonstra que a população apresentou um crescimento pequeno em relação ao censo de 2007, com um aumento de apenas 124 habitantes. Em relação ao crescimento populacional no estado do Rio Grande do Norte a população cresceu consideravelmente, o que atesta que a população acariense tem crescido pouco.

Para construir o trabalho utilizou-se de revisão bibliográfica e de coleta de dados oficiais, consulta em sites de órgãos como o Instituto Nacional do Semiárido (INSA), Ministério do Meio Ambiente (MMA), Instituto do Desenvolvimento Econômico e Meio Ambiente (IDEMA) e Prefeitura. Ainda aplicou-se um formulário simples com questões de múltipla escolha a populares, autoridades, donos de olarias e representantes de órgãos de meio ambiente e pessoas ligadas aos setores produtivos (pecuária, indústria de cerâmica vermelha e olaria).

Foi utilizado o critério de amostragem dentro de procedimentos estatísticos entre os envolvidos com a questão. A pesquisa utilizou-se dos critérios quantitativo e qualitativo de caráter exploratório e descritivo. A apresentação dos resultados é por meio de tabelas e gráficos, como também, de forma descritiva com as informações que não serão possíveis expô-las por gráficos.

\section{REFERENCIAL TEÓRICO}

\subsection{A Desertificação e os seus Núcleos}

A discussão sobre o tema desertificação perdura por várias décadas e permite a reflexão das causas que desembocam neste fenômeno que leva as pessoas a saírem de determinado espaço geográfico e migrarem para outro, deixando alguns espaços com características de deserto ou de semidesertos. Contudo, o Ministério do Meio Ambiente (2004, p. 14), assegura que:

\footnotetext{
O processo da desertificação passou a ser estudado na década de 1970. A maioria dos estudiosos da matéria concorda com as proposições da Coordenadoria de Controle de Doenças (CCD) sobre os fatores determinantes da desertificação, isto é, que é resultante de vários fatores, incluindo variações climáticas e atividades humanas.
}

Dessa maneira, a Convenção das Nações Unidas de Combate à Desertificação e Mitigação dos Efeitos da Seca (1994), garante que:

A desertificação é definida como um processo de degradação ambiental causada pelo manejo inadequado dos recursos naturais nos espaços áridos, semiáridos e subúmidos secos, que compromete os sistemas produtivos das áreas susceptíveis, os serviços ambientais e a conservação da biodiversidade.

Esse processo de desertificação ocorre com maior frequência nas regiões onde a escassez de água é maior e a vegetação não favorece a sobrevivência dos seres vivos nesses espaços, pois a má utilização dos solos por parte do homem também dificulta a sua permanência nestes locais. 
O Brasil é um dos países do mundo onde existe grande concentração de água potável para o consumo dos seres vivos, esse fato deixa sua população despreocupada e até fazendo mau uso desse elemento essencial ao ser humano e outras espécies de seres. Barreto \& Galvão (2010, p. 02) enfatizam que:

\begin{abstract}
No Brasil, há em seu território cerca de $12 \%$ da água doce do mundo, o que o torna detentor das maiores reservas de água potável. A irregular distribuição em seu território, aliada ao caráter predatório de sua exploração e utilização têm se convertido em grande preocupação de ambientalistas do mundo, sobretudo em se tratando de abastecimento de água em diversas regiões do mundo, a exemplo do semiárido nordestino.
\end{abstract}

A região do semiárido, ou seja, a Nordeste e parte de Minas Gerais é a mais penalizada com os efeitos da desertificação, por falta de água, e também economicamente frágil, com infraestrutura deficitária, ficando assim conhecida como núcleos de desertificação, ou seja, as áreas onde a desertificação é mais forte. Segundo Brasil (2005), essa área do semiárido brasileiro atinge uma faixa de $969.589,4 \mathrm{Km}^{2}$.

Nessa ótica, os núcleos de desertificação são aqueles que compõem o polígono das secas que compreende nove estados nordestinos e parte do estado de Minas Gerais. Dessa forma, Perez-Marin et al. apud Accioly (2012) apresenta seis (6) núcleos de desertificação no Nordeste brasileiro, são eles: Gilbués, Irauçuba, Seridó, Cabrobó, Cariris Velhos e o Núcleo do Sertão do São Francisco, desses são reconhecidamente pelo Ministério do Meio Ambiente apenas os quatro primeiros. Deste modo, Accioly $(2011$, p. 2), distribui os tipos de solos dos núcleos de desertificação da seguinte maneira:

Os solos das classes Bruno Não Cálcico, litólico e Planossolo com cobertura vegetal de caatinga hiper-xerófila dominam os núcleos de desertificação de Irauçuba, Cabrobó e Seridó enquanto que no núcleo de Gilbués dominam os solos das classes latossolo, Areia Quartzoza e Podzólicos sob vegetação do tipo campo-cerrado.

Assim, destacaremos os solos das classes de caatinga, voltando para o núcleo do Seridó que atinge os territórios do interior do Rio Grande do Norte e da Paraíba.

\title{
2.2 A Região do Seridó, a Vegetação Caatinga e o Município de Acari
}

A região do Seridó está localizada no interior do estado do Rio Grande do Norte e atinge parte do interior do estado da Paraíba, correspondendo a uma área de $2.987 \mathrm{Km}^{2}$. É uma região com várias peculiaridades destacando-se sua vegetação a caatinga ${ }^{1}$. A figura abaixo apresenta o esboço do mapa do Rio Grande do Norte com o núcleo de desertificação do Seridó com destaque ao município de Acari e circunvizinhos.

1 Vegetação arbustiva, sem folhas na estação seca, típica do Nordeste, norte de Minas Gerais e Maranhão. (Mini Dicionário Aurélio, ed. Nova Fronteira, 4ạ edição, 2001). 
Figura 2: Área da desertificação no interior do Rio Grande do Norte

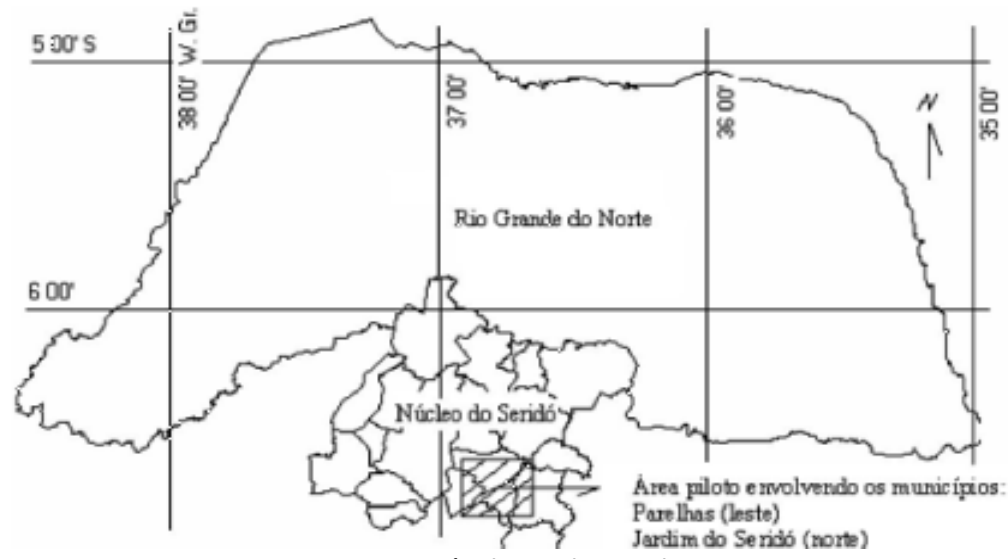

Fonte: Rev. Bras. Eng. Agrícola Ambiental, 2009.

A desertificação neste núcleo está relacionada particularmente a fatores climáticos, processos pedogenéticos e intervenções antrópicas. Conhecida como Núcleo de Desertificação do Seridó (NDS), compreende, no Rio Grande do Norte, os municípios de Acari, Currais Novos, Carnaúba dos Dantas, Cruzeta, Caicó, Equador, Jardim do Seridó, Ouro Branco, Santana do Seridó e São José do Sabugi; e no estado da Paraíba, os municípios de Santa Luzia e de Várzea (PEREZ-MARIN et al apud ACCIOLY, 2012, p. 97).

Essa região é conhecida como semiárida por ser seca, cuja vegetação predominante é a caatinga, com uma espécie de planta de hiperxerófila. A economia local baseia-se na pecuária, na mineração, nas olarias e cerâmicas, e nas faç̧ões que surgem como uma nova oportunidade para incrementar o setor. Thomaz C. e C. da Costa et al (2009, p. 962), ressaltam que "o Seridó-RN/PB é uma das regiões com esta variabilidade, com hipótese de redução da diversidade florística dos fragmentos pela ação antrópica", ou seja, são localidades onde o homem com sua ação destrói o meio ambiente por meio da exploração indevida do solo e dos recursos naturais.

Dentre as opções econômicas já abordadas, identifica-se que algumas delas são prejudiciais à região, pois estão diretamente ligadas ao solo. A pecuária extensiva é uma das fontes de renda mais danosas às áreas susceptíveis a desertificação, como explica Aldrin Martin Perez-Marin et al, (2012, p. 97):

A pecuária extensiva, por sua vez, leva a um consumo de toda a vegetação herbácea deixando o solo descoberto ainda mais tempo nas épocas secas e, quando no início das chuvas, ficando plenamente exposto à erosão pelas chuvas de grande intensidade.

Dessa maneira, o manejo do gado nessa região deve ser repensado e consequentemente, adotadas novas maneiras de lidar com a pecuária para não enfraquecer mais o solo.

Outro fator que prejudica a região são as olarias e cerâmicas que atingem de forma rápida com o fogo das queimadas, com o corte impróprio de lenha e o desmatamento acidentado. Assim, reforçando, o PAN-BRASIL (2004, p. 81), assevera que:

Neste sentido, pesa sobremodo a adoção de técnicas de corte raso da vegetação e o uso do fogo, assim como a grande demanda de madeira nativa para o abastecimento industrial (pólos de cerâmicas, áreas de carvoarias, pólos gesseiros e caieiros) e para o consumo interno (lenha para energia). 
Com isso, percebe-se que as indústrias de cerâmicas e as olarias têm alavancado o processo de desertificação da região devido à ação do homem em busca da lenha. Assim, como todo o Nordeste e parte de Minas Gerais, a região do Seridó é perpassada por esse bioma muito forte e único, a caatinga. Ele sobrevive a grandes períodos de seca, porém sua vegetação absorve rapidamente grandes quantidades de água do solo e do subsolo impedindo que os outros seres vivos se abasteçam por longos períodos. A caatinga do Seridó é predominantemente hiperxerófila ${ }^{2}$ e subdesértica, com clima seco e seu solo rico em minerais. Contudo, Silva et al (2006, p. 69) explica sobre o Seridó que:

\begin{abstract}
Essa região é conformada como uma área em processo de desertificação, posto que apresenta um clima seco e um elevado déficit pluviométrico; possui uma formação geológica rica em minerais e solos que varia entre alta e baixa fertilidade natural, onde a cobertura vegetal é subdesértica e hipexerófila.
\end{abstract}

Desta forma, os maiores fatores de desgaste do solo já identificados posteriormente serão os da desertificação no Seridó, porém os desmatamentos, o mau uso do solo, a pecuária, a vegetação e o clima são elementos que atingem todos os municípios dessa região.

O município de Acari está localizado na Microrregião Seridó Oriental atingindo uma área geográfica de $608,57 \mathrm{~km}^{2}$, a $210 \mathrm{~km}$ da capital Natal, sendo uma das cidades mais antigas do interior do Rio Grande do Norte. É uma das localidades por onde começou o povoamento na região e que guarda um acervo histórico peculiar de relevância. O Instituto Brasileiro de Geografia e Estatística (IBGE) (2010)3 reforça que:

O território do Município era habitado pelos índios cariris, que para ali se deslocaram em virtude das perseguições movidas pelos colonizadores da Paraíba, em fins do século XVII. Em 1737, o fundador do povoado onde está localizada a cidade, Sargento-mor Manuel Esteves de Andrade, obteve permissão do Bispo de Olinda para erguer a capela, consagrada a Nossa Senhora da Guia.

Desde sua colonização, a exploração dessa terra já era notória com a invasão do território pelos vaqueiros que, perseguindo o gado e devastando a vegetação, foram implantando as primeiras cabanas. Por ser uma terra utilizada apenas para passagem e descanso dos tropeiros viajantes, abrigava pequenos mananciais de água. Deste modo, refletindo sobre a colonização de Acari, Galvão (2012, p. 90) pontua que:

\footnotetext{
Nas trilhas do Seridó, feitas pelos aventureiros que buscavam rincões sertanejos, estavam as terras de Acari, onde a natureza oferecia condições para trabalho, descanso e pasto para animais. As vantagens do lugar determinavam parada obrigatória para esses homens que trilhavam a região. Nessa caminhada alguns se fixaram dando origem à comunidade acariense. Dentre as autoridades de relevo, estava o capitão-mor Manuel Esteves de Andrade, a quem se atribui sua criação e, pela história, se reconhece o seu poder como fazendeiro de gado nos domínios territoriais de Acari.
}

\footnotetext{
2 Tipo de vegetação que tem facilidade de se adaptar em solos rochosos, pedregosos e rasos.

3 BRASIL. Instituto Brasileiro de Geografia e Estatística - IBGE. Cidades@: Rio Grande do Norte - Acari: histórico: 2013.
} 
E não diferentemente da origem de outras localidades, às margens de um pequeno poço, paulatinamente foram edificadas as primeiras cabanas do município. Assim, às margens do rio Acauã ${ }^{4}$, abaixo do gargalho, havia um poço de nome Felipe ${ }^{5}$, fonte de água fresca que servia para aliviar a sede dos animais e dos forasteiros que passavam por aquela localidade. Cercada por arbustos de oiticica, favorecia sombra e água natural para os tropeiros viajantes. O poço era abundante de peixes, chamados pelos indígenas de acari, como afirma Rosa (1974, p. 21, grifos do autor):

Acari quer dizer (etimologicamente) acará pequeno. Acari. Peixe de água doce do Brasil, vulgo cari (Loricaria plecostomus) do tupi acari (T.S.), isto é, acará + i, "pequeno". José Machado, “Dicionário Etimológico da Língua Portuguesa”, 1a edição, editorial Confluência, Lisboa.

O município de Acari, desde seus primórdios, apresenta um cenário propício para o desenvolvimento, com uma bela paisagem, com água, animais, terras produtivas e uma vegetação própria da região. Com o desgaste ambiental, a criação do gado, e os desmatamentos para construção de casas e prédios e outras situações foram permitindo que seus habitantes fossem procurando outras localidades para lutar por sua sobrevivência.

A falta de chuva também se caracteriza na região do Seridó desde sua colonização, esse e outros fatores interferem no processo de desertificação até os dias atuais. Refletindo sobre essa questão, Galvão (2012, p. 90) enfoca que:

No período que se sucedeu à demarcação do território acariense, o ambiente rural de todo o Seridó foi alternado por períodos de secas e invernos, mas o seu espaço foi se reproduzindo mediante os benefícios conquistados com a construção de açudes e de uma estrada, ligando o Seridó ao atual município de Carnaubais, consolidando interesses comerciais e econômicos ligados à pecuária bovina.

Com essa alternância de secas ou estiagens na região do Seridó, o homem nordestino, em especial o de Acari, desde seus primórdios, vem se reinventando, ou seja, procurando alternativas para se manter no seu habitat. Desta maneira, algumas das formas mais tradicionais locais são reinventadas, como atividades econômicas, a obtenção de água subterrâneas por meio de poços e o surgimento de novas opções, como facções, as bonelarias e as cerâmicas influenciam para permanência no lugar.

\section{METODOLOGIA}

Esta pesquisa apoiou-se em breve revisão da literatura na coleta de dados e na descrição. A coleta de dados, com estratégias de observação, formulários, análise de documentos e consulta a sites como o da NSA e do MMA.

A coleta se deu por amostragem, sendo selecionados trinta indivíduos, sendo um (1) dono de cerâmica, um (1) gerente de olaria e (2) gerentes de facções e os demais participantes são funcionários de cerâmicas, granja e facções. Os critérios de escolha dos participantes foram à participação direta em área susceptível à desertificação e a novas

4 Acauã. Do tupi aça-uá, contração de aça-uara, o comedor de cabeças (de cobra). Ave de rapina, protetora dos indígenas, inimiga dos ofídios. Vocábulo onomatopéico: a pronúncia lembra a voz de ave, que parece dizer, quando canta: acauã, ou oacauã. O rio que desce do Picui, depois que entra no Rio Grande, recebeu a designação de Acauã. ROSA (1974, p.20).

5 Não encontramos registro sobre o fato em nenhum dos nossos historiadores (MEDEIROS, 1985). 
oportunidades de trabalho no município.

A pesquisa de campo foi realizada nos ambientes de trabalho dos participantes, com autorização dos seus gerentes, sendo escolhidas 30 pessoas de um universo de 300 trabalhadores de cerâmicas, granja e faç̧ões do município para aplicação dos formulários. Nessa perspectiva, se aplicou um formulário simples com questões de múltipla escolha, organizado de acordo com os objetivos da pesquisa. Os formulários são definidos como "uma lista de perguntas organizadas logicamente e é utilizado para juntar informações sobre um tema em particular" (SCHLÜTER, 2005, p. 107). O formulário foi direcionado aos órgãos de meio ambiente local e a pessoas ligadas aos setores produtivos (pecuária, indústria de cerâmica vermelha e olaria).

Nesse contexto, o formulário aplicado continha questões fechadas para a obtenção de respostas claras e completas sobre a desertificação no município de Acari. Também o levantamento de documentação bibliográfica, e com análise dos dados e das informações coletadas foi essencial para o enriquecimento da pesquisa.

O método dedutivo de pesquisa prevaleceu na análise das informações, pois deixa o pesquisador mais à vontade para apreciação dos dados. Desta forma, segundo Prodanov \& Freitas (2013, p. 127) "sugere uma análise de problemas do geral para Dedutivo o particular, através de uma cadeia de raciocínio decrescente".

O critério de amostragem que se utilizou estava intimamente dentro dos procedimentos estatísticos entre os envolvidos com o objeto de estudo da pesquisa. Assim, depois da avaliação da amostra e coleta das informações, os resultados e as conclusões foram projetadas para o universo. Prodanov \& Freitas (2013, p. 127) enfatizam que:

Amostra é parte da população ou do universo, selecionada de acordo com uma regra ou um plano. Refere-se ao subconjunto do universo ou da população, por meio do qual estabelecemos ou estimamos as características desse universo ou dessa população. A amostra pode ser probabilística e não probabilística.

A amostragem da pesquisa foi feita a partir da escolha de donos de cerâmicas, ceramistas e alguns munícipes envolvidos de forma direta nas questões ambientais e da desertificação. A pesquisa utilizou-se do estilo quantitativo e qualitativo de caráter exploratório e descritivo.

A pesquisa quantitativa significa traduzir em números opiniões e informações para classificá-las e analisá-las e requer o uso de técnicas estatísticas; já na pesquisa qualitativa obtêm-se dados que não podem ser traduzidos em números, pois considera que há uma relação dinâmica entre o mundo real e o sujeito (MENEZES e SILVA, 2001).

A apresentação dos resultados é por meio de tabelas e gráficos, como também, de forma descritiva com as informações que não foram possíveis expô-las por gráficos. O estilo quantitativo e qualitativo traduz a seguridade das informações colhidas e demonstra opiniões e a subjetividade das pessoas as quais foram aplicados os formulários.

\section{ANÁLISE DOS DADOS E RESULTADOS}

A pesquisa nos proporcionou averiguar que muitos habitantes de Acari têm algum conhecimento acerca do termo desertificação e do que seja o Meio Ambiente, porém demonstraram insegurança em expressar suas opiniões sobre o assunto. Relatam que o 
meio ambiente se relaciona apenas a elementos naturais, como plantas, chuva, sol e animais. Isso eleva o nível de preocupação, pois se os indivíduos que trabalham de forma direta com espaços que poderiam ser preservados não fazem nada para tanto, o restante da população como será que se encontra em termos de conhecimento?

No quesito 1 do formulário aplicado que se referia à pergunta "Você sabe o que é desertificação?" 60\% afirmaram que sim, porém ficavam provavelmente inseguros, quanto ao conceito para terem a certeza de que era realmente aquilo que eles pensavam ser. $\mathrm{E} 40 \%$ foram categóricos em dizer que não sabem o que é desertificação. Isso comprova que muitas pessoas que habitam a região do semiárido brasileiro não têm conhecimento acerca desse fator em sua própria região.

Em se tratando do grande êxodo de pessoas do município que se deslocam para outras regiões do país, $63,3 \%$ das pessoas que foram aplicadas os formulários asseguraram que o fator determinante para isso é a desertificação. E apenas $36,7 \%$ disseram que a desertificação não interfere na saída dos moradores da região. No tocante ao quesito sobre recursos naturais ambientais preservados no município de Acari, $16,7 \%$ das pessoas interrogadas garantiram que em Acari tem recursos preservados. Já 83,3\% afirmaram que no município não tem recursos ambientais preservados. Esses dados nos levam a refletir sobre três vertentes: 1ㅇ - As pessoas que foram aplicadas os formulários não têm conhecimento acerca de recursos naturais preservados; 20 - O município realmente não tem recursos preservados e 3으 - Não existe política pública de preservação dos recursos ambientais no município.

De acordo com a pesquisa de campo, alguns fatores são considerados como importantes para a saída dos habitantes de Acari/RN para outras localidades, como podemos verificar no gráfico abaixo:

Gráfico 1: Fatores que provocam a emigração dos habitantes de Acari/RN

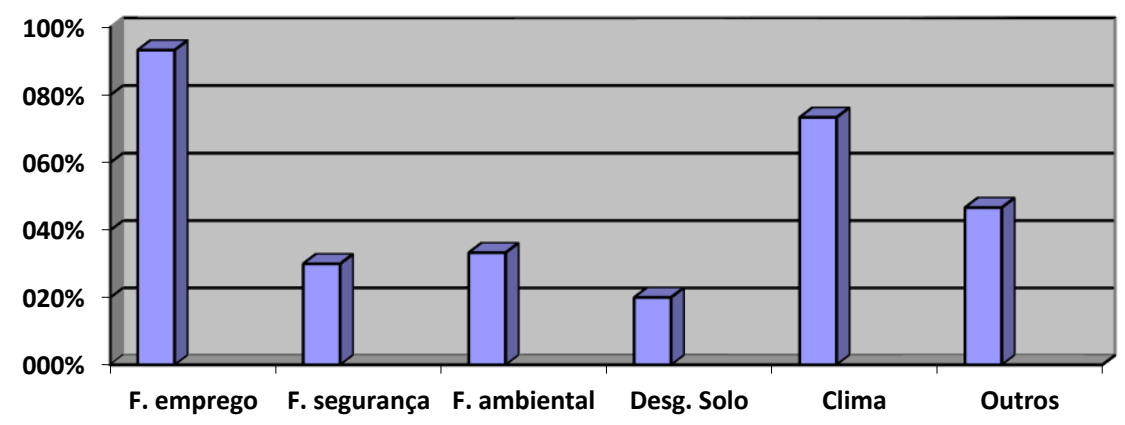

Fonte: Dados da pesquisa de campo, 2014.

Dos participantes da pesquisa, 93,3\% afirmaram que o fator primordial para a saída dos habitantes de Acari é a falta de emprego, isso seguido de fatores relacionados ao clima que teve $73,4 \%$. Esse dado comprova que muitos dos acarienses sofrem com a falta de emprego e saem de sua terra em busca de meio de sobrevivência pessoal e familiar.

O Ministério do Trabalho (2013) enfatiza que uma das regiões mais atingidas com a falta de emprego é a região Nordeste. Muitas são as causas que atingem essa região e ocasiona o desemprego, dentre elas podemos destacar a desqualificação profissional e $a$ falta de oportunidade, bem como de empresas as quais ofertam empregos na localidade e entre outros. 
Outro dado revelado pela pesquisa é que os habitantes de Acari/RN não saem do município só por questões ambientais e muito menos de falta de segurança, mas por motivos como: poluição e falta de emprego.

Quanto às principais causas da desertificação no município os participantes da pesquisa elencaram as seguintes, como se verifica no quadro 1 :

Tabela 1: Causas da desertificação no município de Acari/RN

\begin{tabular}{|l|c|}
\hline \multicolumn{1}{|c|}{ POSSÍVEIS CAUSAS } & Ranque \\
\hline Falta de chuva & 6 \\
\hline Desmatamento & 5 \\
\hline Poluição & 4 \\
\hline Queimadas & 3 \\
\hline Falta de saneamento & 2 \\
\hline Vegetação & 1 \\
\hline
\end{tabular}

Fonte: Dados da pesquisa de campo, 2014.

Diante dos dados expostos no quadro 1 , se faz necessário destacar que os respondentes poderiam escolher mais de uma opção, sendo assim ranqueados do maior para o menor, sendo o maior referente ao número 6 e o menor 1 . Desta forma, verifica-se que a principal causa da desertificação no município de Acari/RN é a falta de chuva seguido do desmatamento. Com um dado tão alto da pesquisa que aponta a falta de chuva como maior causador da desertificação percebe-se que os entrevistados não atentaram para as questões políticas que influenciam de forma direta o fato. É evidente a falta de interesse político para conter os avanços da seca e da desertificação, pois não se cria medidas preventivas contra esses dois fenômenos, consequentemente a necessidade de políticas públicas para a região do Seridó e todo o Nordeste brasileiro.

Com a pesquisa, foi possível analisar os motivos de permanência de habitantes no município de Acari/RN, isso se identifica no gráfico 2 que mostra os fatores que influenciam na permanência dos habitantes.

Gráfico 2: Fatores que influenciam na permanência dos habitantes em Acari/RN

\begin{tabular}{|c|c|}
\hline $\begin{array}{l}1900 \mathrm{ral} \\
1900 \mathrm{ral} \\
1900 \mathrm{ral} \\
1900 \mathrm{ral} \\
1900 \mathrm{ral} \\
1900 \mathrm{ral} \\
1900 \mathrm{ral} \\
1900 \mathrm{ral} \\
1900 \mathrm{ral}\end{array}$ & \\
\hline 口Cid. Pacata & 1900ral \\
\hline 口Facções & 1900ral \\
\hline 口Cerâmicas & 1900ral \\
\hline 口Educação & 1900ral \\
\hline QSupermercados & 1900ral \\
\hline 口Saúde & 1900ral \\
\hline \multicolumn{2}{|l|}{ DEmprego } \\
\hline 口Outros & 1900ral \\
\hline
\end{tabular}

Fonte: Dados da pesquisa de campo, 2014. 
O gráfico mostra que a permanência de grande parte dos habitantes de Acari/RN no município é proveniente dos empregos gerados pelas cerâmicas instaladas na zona urbana da cidade. Isso se apresenta com $76,7 \%$ dos participantes da pesquisa afirmando que as cerâmicas são um suporte para a economia e principalmente para a estabilidade dos munícipes em Acari, seguido das faç̧ões que teve $73,3 \%$ como ramo que cresce no município. As facções ainda são incipientes no município, mas na região do Seridó já é exponencial sua presença em várias cidades.

A realização da pesquisa possibilitou constatar que os munícipes têm uma consciência ambiental, pois quando investigados onde costumam colocar o lixo e a quem compete solucionar os problemas ambientais, ficou notória a preocupação da maioria, como pode ser verificado nos gráficos 3 e 4:

Gráfico 3: Onde você costuma descartar ou depositar lixo?

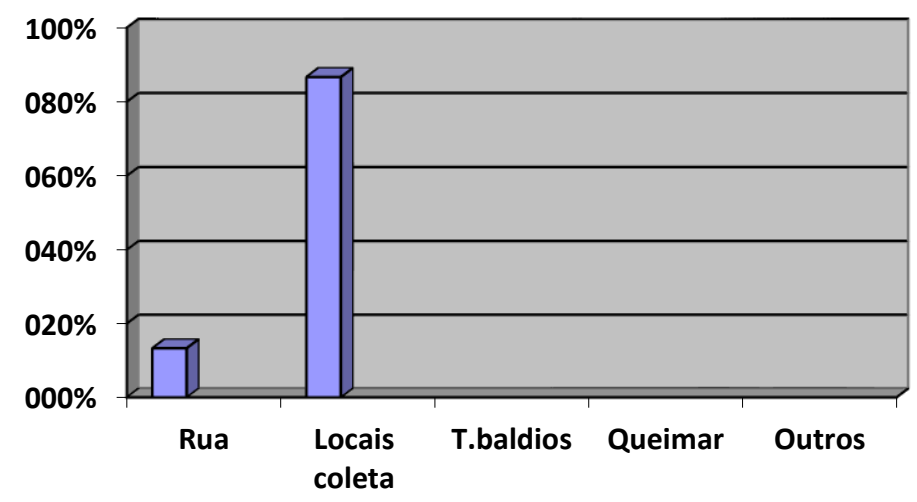

Fonte: Dados da pesquisa de campo, 2014.

O gráfico demonstra que $86,7 \%$ dos participadores da pesquisa costumam descartar ou depositar o lixo nos locais próprios para a coleta e apenas 13,3\% afirmaram que se habituaram a colocar o lixo na rua. Esse dado remete ao título que a cidade de Acari/RN recebeu na década de 70 , do século $X X$, de cidade mais limpa do Brasil em rede nacional de televisão. Para Galvão (2012, p. 160) apud STEINBERG, 2006, o tempo atual permite o cidadão acariense a fazer uma meditação sobre o real contexto da limpeza.

\footnotetext{
No mundo presente, é importante a reflexão sobre sustentabilidade para pensarmos as soluções para a cidade: Acari, cidade mais limpa. Para dar efetividade ao título que a mesma carrega, devem ser considerados os contextos de crise e resistência, na inseparabilidade entre a materialidade historicamente construída, que inclui a natureza e o seu uso, a ação humana e apolítica, pois Ambiente e Território são complementares.
}

Sabe-se que o município já perdeu muito de sua limpeza desde os anos em que recebeu a homenagem de cidade mais limpa, isso se identifica nos vários discursos acerca do município por populares e por estudiosos. Como evidenciado no parágrafo anterior, muitos fatores devem ser considerados, entre eles, o contexto histórico, social e principalmente o político.

A pesquisa apontou que para solucionar os problemas ambientais é necessário o envolvimento de todos os cidadãos acarienses. Assim nos demonstra o gráfico 4: 
Gráfico 4: A quem compete solucionar os problemas ambientais do município?

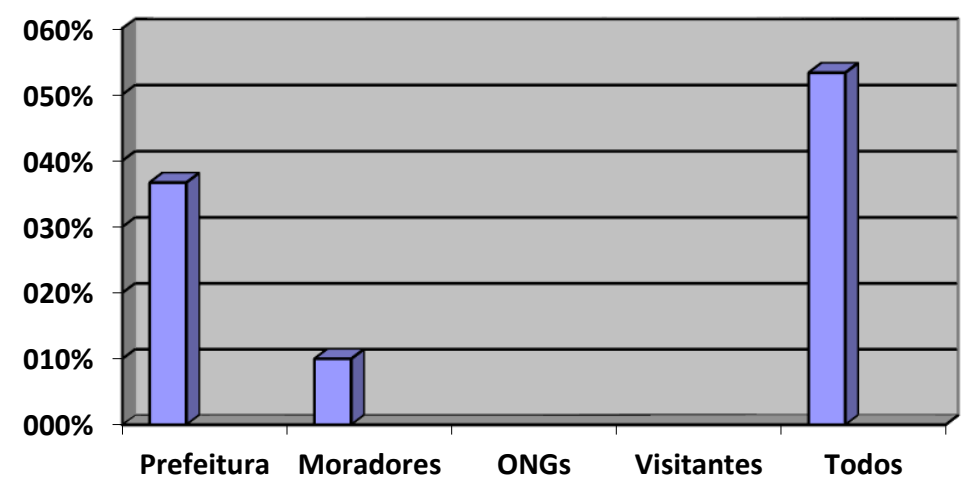

Fonte: Dados da pesquisa de campo, 2014.

O gráfico exibiu que $36,7 \%$ dos participantes afirmam que a solução dos problemas ambientais deve ser da Prefeitura, ou seja, do poder público do município. Apenas $10 \%$ asseguram que a solução desses problemas deve vir dos moradores. E por fim, em sua grande maioria, 53,3\% afirmaram que os problemas com o meio ambiente devem ser resolvidos por todos os que formam a comunidade. Quando esta é consciente de seu papel social, toda a população ganha em termos de saúde, bem estar e saneamento básico.

\section{ANÁLISE AMBIENTAL DO MUNICÍPIO DE ACARI}

Com a pesquisa realizada, foi possível identificar as variadas causas para a desertificação no município de Acari/RN, como também as alternativas de permanência dos munícipes em sua terra natal. Deste modo, percebeu-se que o município de Acari apresenta pontos considerados como intensos que favorece a permanência dos seus moradores.

Dentre esses pontos fortes podemos identificar que em relação a outros municípios, Acari/RN é uma cidade pacata, com atrativos históricos e culturais e conta com um conjunto natural belíssimo às margens do açude Marechal Dutra, como belas formações rochosas, trilhas, inscrições e incisões rupestres, dentre outros.

O município de Acari/RN é bem cuidado pelos seus habitantes e pelo poder público municipal, porém carece de ações que salvaguardem o meio ambiente e proteja os paredões com a arte rupestres e a paisagem natural. O bom costume da população em manter limpas as fachadas de suas residências e o zelo por manter a rua limpa fortalece sua imagem.

As alternativas de permanência identificadas com essa pesquisa evidenciam que o homem que habita essa região sabe como sobreviver aos impactos naturais e ausência de políticas públicas efetivas para combater a seca e conseguinte a desertificação.

Dentre as alternativas de permanência, as facções se destacam como a menos prejudicial ao meio ambiente, pois não desmata a fauna da região e as sobras de tecidos são reutilizadas na produção de artesanato, como tapetes, almofadas, bonecas de pano e pegador de panelas.

\section{SUGESTÃo DE ATIVIDADE PEDAGÓGICA NA ÁREA DE EDUCAÇÃO AMBIENTAL}

Como proposto em um dos objetivos específicos desta pesquisa sugerimos uma atividade pedagógica na área de Educação Ambiental a ser aplicada nas olarias, cerâmicas, 
granjas e facções do município de Acari. Sabendo-se da real importância da formação de uma consciência ambiental nos cidadãos acariense, sugere-se que um especialista da área de Educação Ambiental desenvolva palestras e aplicação de dinâmicas nos horários de intervalos ou horários estabelecidos pela gerência desses estabelecimentos. Ainda, poderá ser aplicada uma enquete entre os funcionários para percepção das maiores dificuldades para manter equilibrada a natureza em seu território de trabalho e consequentemente em sua casa.

\section{CONSIDERAÇÕES FINAIS}

Procurou-se neste trabalho fazer uma reflexão crítica sobre a desertificação no município de Acari/RN e as causas que fazem com que os habitantes desse município permaneçam nele. Para tanto, foi necessária revisão bibliográfica, documental e aplicação de formulário para consultar pessoas ligadas aos setores produtivos, como cerâmicas, olarias, facções e gerentes e donos desses setores.

Esse estudo levantou informações importantes sobre o município e o seu meio ambiente. Identificou-se que o município apresenta um grande potencial para desenvolvimento visto salvaguardar um patrimônio material rico para a história da cidade e do país.

No tocante ao objeto da pesquisa, ou seja, à desertificação, percebeu-se que muitos dizem saber o que é, mas sempre num sentido de questionamento e de dúvidas. Ainda ficou claro que entre as causas de permanência no município se destacam as cerâmicas e olarias e na sequência as faç̧ões. A reversão desse quadro depende do esforço principalmente do poder público na criação de alternativas para geração de emprego e do setor privado no favorecimento de novas iniciativas para o setor produtivo do município. É necessário o envolvimento e conscientização da comunidade no tocante ao meio ambiente, preservação, conservação e educação ambiental.

Partindo dos resultados da pesquisa ficou evidente a necessidade de ações que ajudem a salvaguardar os elementos naturais que compõem o meio ambiente, e assim, que combatam os seus agressores e a urgência na elaboração de políticas públicas ambientais.

\section{REFERÊNCIAS}

ACCIOLY, L. J. O. Degradação do solo e desertificação no nordeste brasileiro do Brasil. Portal Dia do Campo - informações que produz. São Paulo; Fev, 2011. <http://www.diadecampo.com.br/zpublisher/materias/Materia.asp?id=2...>. Acesso em: 18 out. 2013.

BRASIL. Ministério do Meio Ambiente. Secretaria de Recursos Hídricos. Convenção das nações unidas de combate à desertificação. 3 ed. Brasília, 2005.

BRASIL. Ministério da Ciência, Tecnologia e Inovação. Instituto Nacional do Semiárido. Gliricídia: árvore alternativa para o semiárido brasileiro. Brasília, 2012.

BRASIL. Ministério da Integração Nacional. Secretaria de Políticas de Desenvolvimento Regional. Nova delimitação do semi-árido brasileiro: Brasília, 2005. 
BRASIL. Ministério do Meio Ambiente. Secretaria de Recursos Hídricos. Programa de ação nacional de combate à desertificação e mitigação dos efeitos da seca: PAN-Brasil. Brasília: 2004.

BRASIL. Instituto Brasileiro de Geografia e Estatística - IBGE. Censo Demográfico de 2010: características da população e dos domicílios. Acari: 2013.

COSTA, T. C. e C; OLIVEIRA, M. A. J. de. et al. Análise da degradação da caatinga no núcleo de desertificação do Seridó (RN/PB). Revista Brasileira de Engenharia Agrícola e Ambiental. Campina Grande; 961-974. Abril, 2009.

$\begin{array}{lllllll}\text { FRANCO, E. Desertificação do Nordeste. } & \text { N. } & \text { 2, } & 1985 .\end{array}$ <http://200.17.141.110/pos/geografia/geonordeste/index.php/GeoNordeste/article/view /147>. Acesso em: 19 out. 2013.

HOLOS. [on-line]. Rio Grande do Norte, IFRN, 2013. Acari, cidade (mais) limpa. M. L. M. Galvão. Disponível em:

<http://www2.ifrn.edu.br/ojs/index.php/HOLOS/article/viewFile/1694/733>. ISSN 1807 1600. Acesso em: 12 abr. 2014.

HOLOS. [on-line]. Ano 28, Vol. 6, 88. Rio Grande do Norte, IFRN, 2013. A cidade de ACARI/RN: do apogeu ao anonimato. M. L. M. Galvão. Disponível em: <www2.ifrn.edu.br/ojs/index.php/HOLOS/article/download/711/616>. ISSN $1807-1600$. Acesso em: 12 abr. 2014.

PRODANOV, C. C.; FREITAS, E. C. de. Metodologia do trabalho científico: métodos e técnicas da pesquisa e do trabalho acadêmico. 2 ed. Novo Hamburgo: Brasil, 2013.

PROGRAMA DAS NAÇÕES UNIDAS PARA O DESENVOLVIMENTO. Desenvolvimento Humano e IDH. 2012. <http://www.pnud.org.br/IDH/DH.aspx>. Acesso em: 25 out. 2013.

SILVA, E. L. \& MENEZES, E. M. Metodologia da pesquisa e elaboração de dissertação. 3 ed. rev. Atual. Florianópolis: Laboratório de Ensino a Distância da UFSC, 2001.121p.

SANTA ROSA, J. N. Acari: fundação, história e desenvolvimento. Rio de Janeiro: Pongetti, 1974. 144p.

SILVA, A. C. C. da; BARBOSA JUNIOR, A. F. et al. Educação ambiental e geografia: uma experiência interdisciplinar no Seridó potiguar. Revista Holus. Rio Grande do Norte; 67-75. Out, 2009.

SCHLÜTER, R. G. Metodologia da pesquisa em turismo e hotelaria. São Paulo: Aleph, 2005. 